\title{
Impulse dynamics of coupled synchronous neurons
}

\author{
Epaminondas Rosa Jr., Samuel Krueger \\ From Twenty First Annual Computational Neuroscience Meeting: CNS*2012 \\ Decatur, GA, USA. 21-26 July 2012
}

Synchronization of neurons remains a topic of great interest due in part to practical implications of relevance to desirable as well as to undesirable states. Neural synchrony can be related, for instance, to healthy activity as in the case of the various stages of sleep [1], but can also be related to pathological processes as in the case of Parkinson's disease [2]. Even though the enormous scientific and technological advances we have been witnessing over the past years helping us understand better the mechanisms behind neurological activities, there is still much to learn, in a context where mathematical models are potentially capable of making important contributions.

This presentation comprises two parts. Part 1 describes a set of neuron model equations based on the HuberBraun (HB) work which was originally intended for studying temperature sensitive neurons [3]. However, the HB equations have been proven to be applicable to a wide range of situations, including studies aimed at clarifying

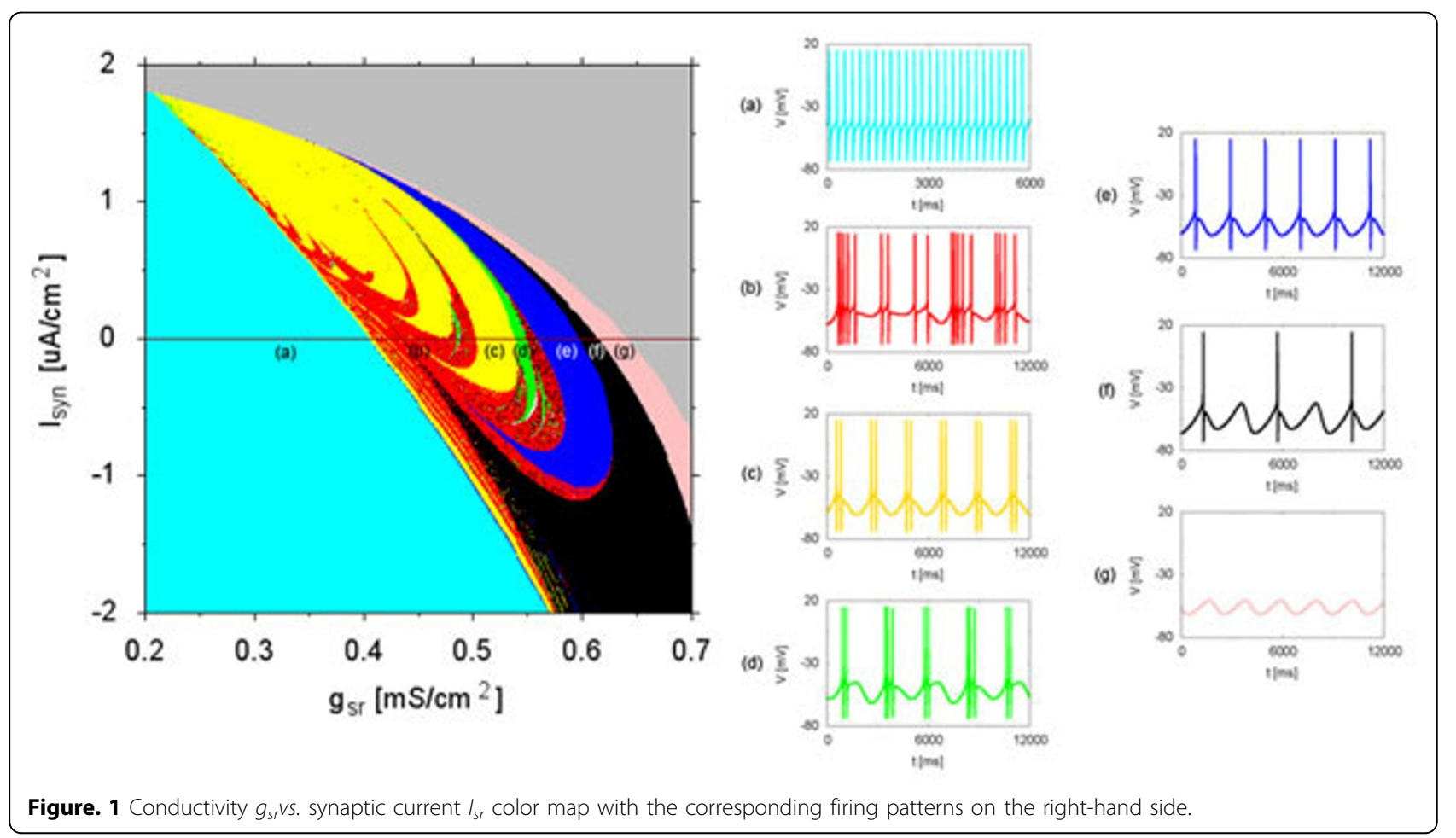

* Correspondence: erosa@ilstu.edu
Department of Physics, Illinois State University, Normal, IL 61790, USA 
the mechanisms controlling the different neural firing regimes and transitions between them [4] as illustrated in Fig. 1, as well as neuropsychiatric disorders [5], to name a few. Part 2 details how these neurons can get in synchrony and shows patterns of synchronous behaviors associated with a variety of coupling values and with the firing regimes the neurons were at before being coupled. The argument will be made regarding neuropathologies such as deep depression, for example, in relation of pharmacological treatments capable of altering neuronal firing rates, therefore affecting their synchronization capability.

Published: 16 July 2012

\section{References}

1. Postnova S, Layden A, Robinson PA, Phillips AJK, Abeysuriya RG: Exploring Sleepiness and Entrainment on Permanent Shift Schedules in a Physiologically Based Model. J Biol Rhythms 2012, 27:91-102.

2. Park C, Worth RM, Rubchinsky LL: Fine temporal structure of beta oscillations synchronization in subthalamic nucleus in Parkinson's disease. J Neurophysiol 2010, 103:2707-2716.

3. Huber MT, Krieg JC, Dewald M, Voigt K, Braun H: Stimulus Sensitivity and Neuromodulatory Properties of Noisy Intrinsic Neuronal Oscillators. Biosystems 1998, 48:95-104.

4. Postnova S, Wollweber B, Voight K, Braun H: Impulse pattern in bidirectionally coupled model neurons of different dynamics. Biosystems 2007, 89(1-3):135-42

5. Postnova S, Rosa E Jr, Braun H: Neurones and Synapses for Systemic Models of Psychiatric Disorders. Pharmacopsychiatry 2010, 43(Suppl 1): S82-S91.

doi:10.1186/1471-2202-13-S1-P102

Cite this article as: Rosa and Krueger: Impulse dynamics of coupled

synchronous neurons. BMC Neuroscience 2012 13(Suppl 1):P102.

\section{Submit your next manuscript to BioMed Central} and take full advantage of:

- Convenient online submission

- Thorough peer review

- No space constraints or color figure charges

- Immediate publication on acceptance

- Inclusion in PubMed, CAS, Scopus and Google Scholar

- Research which is freely available for redistribution

Submit your manuscript at www.biomedcentral.com/submit 